\title{
Assumir o papel do Pail: intervenção psicoterapêutica na adolescência
}

\author{
Olga Melo ${ }^{\mathrm{a}^{*}}$, Catarina Pinheiro Mota ${ }^{\mathrm{a}, \mathrm{b}}$, Susana Dias Silva ${ }^{\mathrm{c}}$ \\ a Universidade de Trás-os-Montes e Alto Douro, Portugal \\ ${ }^{b}$ Centro de Psicologia da Universidade do Porto \\ 'ACES Alto Tâmega e Barroso, Centro de Saúde de Chaves n 1
}

\begin{abstract}
Resumo: $O$ presente estudo de caso aborda a vivência de um adolescente de 15 anos de idade, destacando a angústia e a ansiedade de separação face à figura paterna, recentemente reclusa por motivo de parricídio. 0 processo deu início com uma atitude defensiva, relutante e desconfiada por parte do paciente, verificando-se um sofrimento significativo na gestão interna das vivências passadas e um sentimento de estigmatização interna e externa. A avaliação realizada traduz um jovem adolescente resiliente e bem adaptado, contrariamente ao que seria de esperar diante das recentes vivências. Todavia, ressaltam alguns sinais de vivência depressiva, nomeadamente de abulia, astenia e anedonia, acrescidos a sentimentos de preocupação e desesperança face ao futuro. É proposta uma intervenção psicológica por meio de psicoterapia breve de orientação psicodinâmica por forma a permitir resolver conflitos internos que podem comprometer o desenvolvimento da personalidade e estabelecimento de relações interpessoais. Além da diminuição da sintomatologia, pretendeu-se clarificar, organizar e transformar os conflitos internos em elementos sustentáveis. O processo de psicoterapia, em paralelo com as mudanças na dinâmica relacional do jovem permitiram que ocorressem mudanças significativas, destacando-se uma atitude menos defensiva e capacidade para pensar sobre si, tolerar e elaborar seus sentimentos e suas emoções.
\end{abstract}

Palavras-chave: adolescência, separação, conflitos internos, psicoterapia.

\section{Introdução}

Bruno (nome fictício) tem quinze anos de idade, é natural do interior norte de Portugal, onde frequenta o $8^{\circ}$ ano do $3^{\circ}$ ciclo numa Escola Preparatória de sua cidade. Atualmente reside em meio urbano, com a mãe de 41 anos, jardineira de profissão, e a irmã de 21 anos, que se encontra desempregada.

Há cerca de um ano antes do início de acompanhamento, Bruno confrontou-se com alterações na dinâmica familiar, respeitante à reclusão da figura paterna na sequência de um parricídio. O processo desenvolvimental de Bruno remete para vivências pautadas por episódios de violência, contacto com armas brancas e armas de fogo, assim como os frequentes confrontos perante elevados conflitos entre a figura paterna e o avô paterno. Anteriormente ao homicídio do avô paterno, Bruno sofreu ameaça de morte, perpetrada pelo avô, quando de uma discussão entre este e o pai do paciente.

Bruno manifesta pontualidade nas sessões, apresen-tando-se vígil, de aspeto limpo e asseado, em concordância e coadunante face à faixa desenvolvimental em que se encontra. Mantém contacto ocular, discurso claro e fluente, evidenciando atitude relacional e colaborante, ainda que tenha apresentado numa fase inicial postura retraída e defensiva. Denotou-se, também, humor deprimido, ressaltando estado de angústia e ansiedade, acrescido de

* E-mail: olga_soaresmelo@hotmail.com dificuldade em expressar sentimentos e emoções no início do processo terapêutico.

\section{Motivo e pedido do encaminhamento}

Bruno foi encaminhado para a consulta de psicologia pela sua Médica de Família, com o motivo de reatividade diante da reclusão do pai em Fevereiro de 2011.

$\mathrm{O}$ pedido do paciente vai ao encontro do motivo de encaminhamento, no sentido de percecionar comprometimento relacional face ao estigma social, pelo facto de se tratar do filho de um homicida (sic). Manifestou mal-estar, desconforto e ansiedade, quando confrontado por parte de algumas pessoas perante o sucedido em sua família. Ressaltando o facto de colegas, familiares e sociedade em geral tenderem a aproximar-se para versarem $o$ assunto (sic).

Bruno manifesta, concomitantemente, apreensão e pertinência em melhorar o rendimento escolar, com o objetivo de transitar para o $9^{\circ}$ ano de escolaridade.

\section{História desenvolvimental e familiar}

Bruno é o filho mais novo de uma fratria de dois irmãos, tem uma irmã mais velha com 21 anos com quem mantém uma boa relação ainda que pouco aberta. Trata-se de um filho planeado e muito desejado por parte de ambas 
as figuras parentais (sic). Nasceu de parto por cesariana, no final do tempo previsto de gestação, tendo nascido com peso e comprimento abaixo da média expectável para um bebé recém-nascido. Foi alimentado artificialmente, tendo iniciado a marcha aos 13 meses, sendo que desenvolveu a fala mais tardiamente. Bruno manteve, desde sempre, bom relacionamento com as figuras parentais, a figura fraterna e grupo de pares, ainda que tenha evidenciado precocemente temperamento introvertido, tendo-se o mesmo agravado face à reclusão do pai. Desde o nascimento até a dita reclusão, Bruno residiu com a família nuclear em meio rural $^{1}$, num ambiente onde todos se conhecem e têm acesso às vivências dos demais. Desde então, passou a residir em meio urbano, juntamente com a mãe e a irmã.

Bruno frequentou o ensino regular, desde o $1^{\circ}$ ciclo, tendo reprovado no $2^{\circ}$ ano do ensino básico. Apresenta avaliações satisfatórias, na maioria das áreas curriculares, beneficiando de apoio nas áreas onde evidencia maior dificuldade, pelo facto de auferir resultados negativos nas mesmas.

Manteve desde sempre bom relacionamento no seio familiar, tendo desenvolvido, desde a primeira infância, forte relação proximal com a figura paterna diante da maior disponibilidade desta, por motivo de doença, sendo que a mãe teve necessidade de ir trabalhar para escorar a sustentabilidade económica da família.

Ao longo de sua infância, Bruno partilhou juntamente com a figura paterna grande cumplicidade, acompanhando a mesma na realização de trabalhos domésticos, agrícolas e atividades de lazer. Por outro lado, Bruno vivenciou desde sempre, e com relativa frequência, elevados conflitos e desavenças entre a figura paterna e a do avô, tendo-se os mesmos intensificado a partir de 2008 (tinha o paciente 11 anos). Na época o avô dirigiu ameaças relativamente à vida do neto, facto que ocasionou a exaltação do pai, levando ao agravamento das desavenças entre eles. As disputas entre o avô e os pais do paciente foram sempre constantes, motivadas por questões económicas e contendas de propriedade de bens, sendo que as ameaças a Bruno enquanto figura sucessora do pai culminaram num sentimento de maior afastamento e relutância face ao avô. Para Bruno, a figura do avô esteve sempre pouco presente, manifestando reduzido apreço pela sua companhia, ao invés do que sucedia com o pai, significativamente apoiante e uma figura com quem sempre se identificou, considerando-o um exemplo para si (sic).

O paciente nunca foi resguardado dos episódios de violência, tendo assistido desde sempre aos conflitos, às ofensas e ameaças entre pai e avô, desenvolvendo medo e a perceção de que algo de pior pudesse vir a suceder (sic). Cresceu num ambiente que lhe permitiu o conhecimento e convivência, desde cedo, com um conjunto diversificado de armas brancas e de fogo em casa do avô.

Em fevereiro de 2011, Bruno assistiu ao derradeiro conflito entre o pai e o avô, tendo este disparado sobre

1 Como meio rural entende-se uma aldeia situada no interior nordeste de Portugal, a cerca de $10 \mathrm{kms}$ da cidade mais próxima com cerca de 11000 habitantes (meio urbano). o pai do paciente. Na continuidade, em legítima defesa o pai de Bruno atingiu mortalmente o pai (avô de Bruno) com uma arma branca. Na sequência do parricídio, o pai de Bruno foi sujeito a reclusão preventiva, até aguardar a sentença do tribunal em julgamento.

Desde então, Bruno confrontou-se com um conjunto de alterações em seu quotidiano familiar na sequência da reclusão parental, com repercussão na esfera, relacional, social e económica, exortando-lhe angústia e sofrimento. Acresce o facto de ter conhecimento relativamente a represálias feitas por outros reclusos ao pai, no estabelecimento prisional onde se encontrava detido.

Após a reclusão da figura paterna, Bruno manifesta retraimento social, isolamento e um quotidiano distribuído entre casa, escola e visitas ao pai, ao fim de semana. Não evidencia vontade em estabelecer relações interpessoais e envolver-se em atividades lúdicas e recreativas.

Presentemente o pai de Bruno foi transferido de estabelecimento prisional, beneficiando atualmente de melhores condições no estabelecimento onde se encontra detido, acrescidas da possibilidade em exercer atividades laborais e recreativas no espaço exterior circundante ao estabelecimento.

\section{Avaliação psicológica}

Após um primeiro contacto e observação do paciente ao longo das primeiras sessões, Bruno revelou uma atitude defensiva patenteada em sua expressão facial. Ressaltaram sentimentos de desesperança face ao futuro, resultantes da privação física e temporal de alguém significativo para si.

Ainda que Bruno evidenciasse dificuldade em extravasar sentimentos e emoções, denotou angústia, ansiedade e raiva evidenciadas em alterações somatoformes expressas por palidez e calafrios. Ressaltou uma atitude rígida e austera diante do futuro. Tornou-se pertinente a recolha de mais informação acerca do funcionamento interno do paciente, a partir da realização de uma avaliação psicológica. A avaliação psicológica assumiu neste contexto um papel relevante no sentido de clarificar aspectos da vivência e estrutura de funcionamento interno do paciente, constituindo um momento de pré-terapia que foi explicado e devolvido junto do mesmo.

Num primeiro momento de avaliação, com a finalidade de compreender melhor a estrutura de personalidade e atual estado emocional do paciente, foi utilizado o Roberts Apperception Test for Children (McArthur \& Roberts, 1982) a partir de uma compreensão das perceções de Bruno em situações interpessoais e em contexto familiar.

Os resultados revelam que, ao nível das escalas adaptativas, Bruno apresenta níveis médios, à exceção da imposição de limites e do suporte de outros que se encontram abaixo da média. Os valores baixos na escala da imposição de limites podem evidenciar que, de momento, as figuras parentais se encontram menos disponíveis para apoiar o paciente. Relativamente à escala suporte de outros, 
esta poderá traduzir de igual forma a perceção do paciente face à pouca disponibilidade dos outros para lhes dar suporte. Contudo, a procura de ajuda nos outros pode estar, também, condicionada pelas suas características pessoais. Contrariamente, a escala de suporte da criança encontra-se ligeiramente elevada, evidenciando que Bruno denota recursos internos consideráveis para enfrentar as adversidades do meio.

Diante de possíveis vivências adversas, Bruno parece ser autossuficiente, evidenciando maturidade para recorrer mais a si e aos seus recursos, ao invés de percecionar a ajuda dos outros, podendo denotar pouca disponibilidade destes para lhe prestar apoio e atenção. Porém a elevação desta escala pode evidenciar defensividade significativa, podendo justificar-se atendendo ao facto de Bruno se encontrar na fase da adolescência. Ainda que os outros possam denotar vontade de apoiá-lo, Bruno parece retrair-se e recusar ajuda devido à necessidade interna de demonstrar ser capaz e autossuficiente.

Ao nível das escalas clínicas, Bruno apresenta uma elevação, não significativa, de depressão e ansiedade. A elevação da escala depressão prende-se com a sintomatologia depressiva que tem vindo a experienciar, tais como abulia e apatia. Na escala de ansiedade, a elevação é manifesta por situações de desconforto, preocupação e medo. Estes resultados podem dever-se às recentes vivências do paciente, nomeadamente devido à reclusão da figura paterna na sequência do homicídio do avô de Bruno, factos que provocaram grandes alterações no quotidiano do paciente. A acrescer a estes factos, o paciente evidencia grande preocupação relativamente ao baixo rendimento escolar, receando ficar retido no presente ano letivo, o que recria em si um sentimento de não cumprimento de suas responsabilidades perante o pai.

No que concerne às figuras significativas, verifica-se que os pais de Bruno são figuras importantes para si, nas quais perceciona algum apoio. Bruno parece ainda atribuir importância aos pares, ainda que o mesmo não pareça perceber este contexto como fonte de segurança. Recentemente percebe no grupo de pares alguma ansiedade e agressividade, contudo não significativa, podendo ser considerada normativa atendendo à fase desenvolvimental em que se encontra. Este facto ressalta o pouco envolvimento e investimento do paciente no exterior, estando presentemente mais voltado para si.

Deve ressaltar-se que Bruno nunca mencionou a figura fraterna, podendo esta ausência significar que, presentemente, não mantém uma relação proximal com a irmã. Isto pode justificar o facto de o paciente descrever diferenças nos sentimentos face ao homicídio do avô e posterior reclusão do pai, tendo a irmã sentido consideravelmente a perda do avô, ao invés de Bruno, que sofreu e sentiu significativamente o afastamento do pai, na sequência de sua reclusão.

A partir de uma análise de conteúdo, pode verificar-se a falta de comunicação e abertura no seio familiar, evidente na ausência de diálogo entre as figuras ao longo de todos os cartões. Os acontecimentos na família de Bruno parecem não ser discutidos em família, assim como as demais problemáticas, isto é, parece não existir partilha de sentimentos e emoções, mas um interiorizar e acumular dos mesmos. Bruno projetou-se nos cartões evidenciando ausência de defensividade, denotando contacto com a realidade, ficando patente um pedido de ajuda, ainda que inconsciente, relativamente às recentes vivências.

Em suma, verifica-se que, face a essas vivências significativas em sua vida, Bruno evidencia características de um jovem bem adaptado, ainda que muito voltado para si e pouco para o exterior. Contudo, mostra capacidade para identificar problemas a um nível cognitivo apropriado à fase desenvolvimental em que se encontra. Bruno manifestou capacidade para perceber e confrontar os problemas de forma realista, tendo mantido comportamento apropriado ao longo de toda a prova.

Com a finalidade de avaliar a intensidade de sofrimento e existência de alterações psicopatológicas e psicossomáticas, foi ainda aplicado o Sympton Distress Checklist 90- Revised (SCL-90) (Degoratis, 1994).

Os resultados globais da prova indicam sofrimento psíquico, amplitude e diversidade de psicopatologia e intensidade somática ligeira a moderada, comparativamente com indivíduos do mesmo género da população não clínica.

No que respeita às dimensões psicossomáticas, Bruno auferiu pontuações de carácter moderado, nas dimensões Obsessão-compulsão, respeitantes a comportamentos, pensamentos e impulsos que o sujeito considera absurdos e indesejados, de intensa angústia e difíceis de resistir, evitar ou eliminar; Sensibilidade interpessoal, que se refere à incomodidade e inibição nas relações interpessoais, e Psicoticismo, que, no caso de Bruno, diz respeito a sentimentos de alienação social.

Assim, observou-se uma diversidade do quadro psicopatológico variando de intensidade muito ligeira a moderada. Estes resultados podem ser justificados atendendo a características de personalidade do paciente, como a introversão e timidez, assim como pela perceção de curiosidade e estigma por parte dos outros face à reclusão do pai. $\mathrm{Na}$ generalidade dos resultados obtidos, Bruno não revelou resultados significativos a nível de alterações psicológicas e psicossomáticas.

\section{Diagnóstico psicológico}

O diagnóstico não se apresenta como um requisito prévio do processo terapêutico, sendo que pode, inclusive, em alguns casos, condicionar a evolução do paciente. Quando o terapeuta tem conhecimento das reais causas do sofrimento do paciente, o diagnóstico é prescindível (Rogers \& Kinget, 1975).

Segundo McWilliams (2005), o diagnóstico não é prioridade quando o terapeuta realiza uma compreensão exaustiva do indivíduo, uma vez que a focalização no mesmo tende a prejudicar a relação terapêutica, imputando-lhe um cariz intelectualizado. Note-se que a avaliação tornou- 
-se pertinente dado que pareciam existir aspectos da vivência de Bruno pouco claros e de difícil acesso. A recorrência aos meios auxiliares de diagnósticos permitiu uma análise dos sentimentos patentes nos sintomas, facto que foi devolvido ao paciente, facilitando sua abordagem no espaço da terapia, ao invés do que sucedia no seio familiar. Deste modo, após análise de um conjunto de informação significativa a partir da observação, recolha da história clinica e avaliação realizada, observa-se que Bruno é um jovem adolescente resiliente e bem adaptado, contrariamente ao que seria de esperar face às recentes vivências. Contudo, ressaltam alguns sinais de vivência depressiva, nomeadamente de abulia, astenia e anedonia, acrescidos a sentimentos de preocupação e desesperança perante o futuro.

Bruno encontra-se num momento de avaliação, análise e gestão interna face às mais recentes vivências e perdas, bem como numa fase decisional do seu percurso de vida a médio e longo prazo, pautado pela ausência de uma figura paterna significativa. Apoia-se principalmente em si e em seus recursos internos, revelando menos disponibilidade para procurar ajuda em terceiros. Denota introversão e isolamento estando, presentemente, pouco disponível para o exterior. A reclusão do pai apresenta-se como uma realidade que lhe provoca angústia e sofrimento, ainda que de momento Bruno manifeste vontade e disponibilidade para enfrentar as problemáticas familiares e ocupar o lugar da figura paterna, facto que pode gerar incongruências dado que se trata de um jovem adolescente que carece de uma estrutura interna suficientemente robusta.

A falta de comunicação no seio familiar, face à reclusão da figura paterna, parece dificultar a possibilidade de Bruno expor e extravasar sentimentos e emoções pela ausência do pai. Da separação da figura paterna sobrevieram consequentes alterações na dinâmica familiar e dificuldades associadas. Ressalta ansiedade e preocupação diante do futuro, principalmente no que concerne ao rendimento escolar.

\section{Análise compreensiva da problemática}

A família constitui uma instituição capaz de aportar suporte, segurança e bem-estar, sendo um contexto potencializador do desenvolvimento humano (Pratta \& Santos, 2007). Todavia, ao longo de seu ciclo vital, as famílias podem ver-se delimitadas por obstáculos, aduzindo dificuldades em superar os problemas, ainda que tenham funcionado bem, até o momento em que são confrontadas com crises (Barker, 2000). As experiências vivenciadas na família contribuem para seu crescimento individual, pelo contacto com uma panóplia diversificada de sentimentos e emoções, tais como o afeto, dor, raiva, mágoa, entre outras. Tais experiências asseveram aprendizagens substanciais para a prática futura (Pratta \& Santos, 2007).

Bruno é um jovem adolescente confrontado com vivências negativas de cariz significativo no seio familiar. Experienciou alterações na dinâmica familiar resultante da continuidade de conflitos internos e no culminar de violên- cia física e emocional extrema, que finda com a privação da presença física do pai. O parricídio assume para si o resultado de uma relação destruturada do avô para com o pai, destacando o sentimento de injustiça, não pela perda do primeiro, mas pelo castigo atribuído ao pai por resguardar a família. Fica patente em Bruno um sentimento, ainda que inconsciente, de culpabilidade inerente ao desfecho deste episódio, também porque ele mesmo em parte poderia ter contribuído para o mesmo, dado que havia sido igualmente ameaçado de morte pelo avô. Neste sentido, em sua fantasia a responsabilidade dos acontecimentos e o papel de proteger a família acabou por recair de todo no pai. Nesta medida, agora que o pai não está, surge a necessidade em Bruno de assumir seu papel, ainda que simbolicamente, como que avocando a partilha da imputabilidade dos acontecimentos. Tornou-se evidente que a reclusão do pai de Bruno foi percebida como um acontecimento que teve grande impacto em si, não só pelo afastamento físico, mas pelo significado que a vivência acarreta, nomeadamente o sentimento de injustiça e culpa inerente a esta perda. Durante o período da adolescência, a autonomia do indivíduo não é fortalecida a partir do isolamento das figuras parentais, mas de uma relação pautada pela contiguidade e perseverança com os mesmos (Atger, 2004). Segundo Marcelli e Braconnier (1989), ainda que a adolescência se caracterize pela procura de autonomia e independência, é também caracterizada por uma profunda dependência do contexto familiar vivenciado ao longo da infância.

Bruno vivencia um momento particularmente difícil em sua vida. A ausência do pai assemelha-se a uma perda, comparável a um processo de luto de alguém que não faleceu mas com quem o contacto se encontra limitado. O contexto familiar pode apresentar-se como um fator desencadeante de sintomatologia ansiogénicas e depressiva no adolescente como reação a uma separação, perda ou privação (Marcelli \& Braconnier, 1989).

Bruno sente-se sozinho face às mais recentes vivências, gerando um conflito interno em si. Manifesta retraimento e hostilidade perante aqueles que manifestam curiosidade pelo ocorrido, sentindo-se condicionado e invadido em sua privacidade. Os acontecimentos ocorridos parecem não ser discutidos em família, assim como as demais problemáticas, não existindo partilha de sentimentos e emoções, mas um interiorizar e acumular dos mesmos. Os problemas que surgem no sistema familiar são períodos de crise, lesados pela instabilidade e estresse às quais, na contemporaneidade, a família, é cotejada, até que seja restabelecida, novamente, a homeostasia (Fernandes, 2005).

Bruno denota vontade falar com a mãe e a irmã da temática que o preocupa, porém as mesmas não mostram abertura e disponibilidade suficiente, tratando-se de um assunto interdito no seio familiar. Neste sentido, a falta de comunicação no seio familiar pode acarretar ou intensificar dificuldades, particularmente a nível relacional, e deste modo comprometer o bem-estar psicológico do adolescente (Pratta \& Santos, 2007). Este trabalho foi realizado ao longo da terapia, pelo que a atitude de resistência inicial de Bruno 
foi-se dissipando, dando lugar à expressão e elaboração dos sentimentos, que oscilavam da raiva e revolta até a perseverança e esperança. Ressalta alguma rivalidade fraterna expressa por conflitualidade e perceção de pouco apoio na mesma. Segundo Fernandes (2005), as perturbações ou alterações num elemento de uma família afeta a dinâmica familiar e concludentemente todos os restantes elementos que dela fazem parte, inclusive o subsistema da fratria.

Face ao ocorrido e à incerteza do futuro, Bruno evidencia defensividade e preocupação, expressando angústia permanente, ansiedade, e sinais de astenia, abulia, apatia e anedonia. Qualquer acontecimento de vida ou mudança na vida do adolescente é algo que se apresenta como uma contrariedade, pelo facto de se tratar de algo imposto e não uma mera opção, o que pode suscitar o desenvolvimento de um estado deprimido (Marcelli, 2002). De acordo com Matos (2007), a reação depressiva ocorre na sequência da perda afetiva, expressa pelo adolescente por um misto de dor, abatimento e raiva, revolta.

De momento Bruno aduz pouco envolvimento e investimento no exterior, estando presentemente mais voltado para si, agravando características individuais tais como timidez e introversão. $\mathrm{O}$ adolescente deprimido não permite que um objeto intermediário substitua o objeto do passado relativamente ao qual sente perda, pelo facto de nele ainda se encontrar fincado, o que pode dificultar 0 processo de luto (Marcelli, 2002).

Com o intuito de vingar o pai, evidencia desejo de dar continuidade ao trabalho e às funções exercidas pelo mesmo, assumindo postura adultomorfa, acrescida do desejo de a figura paterna não ser imputada por algo que Bruno considera injusto. Porém, o arrebatamento de determinados papéis e determinadas funções no seio familiar pode representar um custo considerável para aquele que assume esse papel em particular (Barker, 2000). Perante realidades difíceis, os indivíduos manifestam dificuldades em lidar com as mesmas, combinando negação com pensamento mágico (McWilliams, 2004).

Presentemente Bruno desenvolve uma postura pautada pelo assumir de responsabilidades várias para que a figura paterna se sinta orgulhosa, nomeadamente um bom desempenho académico. As transformações a que a família pode estar sujeita, podem resultar em modificações nas vivências, perceção e formação do jovem adolescente, com influência a nível afetivo, social e no que concerne a futuros projetos de vida (Pratta \& Santos, 2007).

Bruno evidencia resiliência expressa numa conduta activa, com atitudes e estratégias pessoais para se defender e enfrentar a vida, o que se apresenta como um fator protetor face ao desenvolvimento desadaptativo.

Pretende-se que no final do processo terapêutico o paciente esteja capaz de gerir internamente a vivência emocional de separação e perda, potenciando sua autonomia e individuação (Hobbs, 1999).

De acordo com McWilliams (2004), existem situações e problemáticas inalteráveis, parcamente susceptíveis de modificação terapêutica, contudo é exequível a adapta- ção a aspetos de vida imutáveis a partir do desenvolvimento de estratégias compensatórias. A adaptação implica transformar a negação e ideias mágicas em luto e coping, assim como substituir crenças por explanações realistas, permitindo o estabelecimento e desenvolvimento de melhores e mais concretas relações com base na aceitação de aspetos imutáveis da vida de cada um.

\section{Objetivo da terapia}

Considerando as vivências, a problemática, fase desenvolvimental e as características da personalidade de Bruno, optou-se por uma abordagem terapêutica baseada na psicoterapia breve de orientação psicodinâmica.

A intervenção curta e focalizada permite fomentar um processo de desenvolvimento possante, produzindo mudanças consistentes e duradoiras no paciente (Hobbs, 1999). Apesar de breve, a psicoterapia breve de orientação psicodinâmica permite ao paciente a possibilidade de refletir acerca de suas vivências, atribuindo-lhes significado. Ou seja, não incide na simples diminuição e resolução de sintomas, mas empreende a autoconsciência, compreensão e controlo pessoal. A intervenção dinâmica ajuda a resolver conflitos internos que podem comprometer o desenvolvimento da personalidade e estabelecimento de relações interpessoais, favorecendo mudanças progressivas da personalidade (Hobbs, 1999).

A psicoterapia breve de orientação psicodinâmica apresenta-se particularmente útil em jovens que evidenciem perturbações do foro emocional. No início do processo o jovem adolescente exibe pouca capacidade para expressar suas dificuldades, bem como para identificar o problema e aludir a existência de preocupações psicológicas. Porém, ultrapassada qualquer forma de resistência inicial, o paciente responde melhor à psicoterapia breve de orientação psicodinâmica pelo facto de se tratar de uma terapia curta, ativa, focalizada no problema e orientada para o presente, sendo especialmente dirigida às emoções ao invés de cognições (Hobbs, 1999).

Ressalta-se o facto de presentemente Bruno vivenciar um processo de luto, pautado pela perda emocional que a separação acarreta. Como tal, torna-se pertinente favorecer no paciente condições para que seja capaz de identificar, experimentar e aceitar suas vivências, emoções e seus sentimentos (Rogers \& Kinget, 1975).

A psicoterapia apresenta-se como uma grande ajuda na medida em que o paciente perceciona a consulta como um espaço onde se sente compreendido e pode elaborar os conflitos internos. Ainda que alguns aspetos da vida não admitam modificações, pelo processo terapêutico é possível promover a transformação e adaptação do indivíduo à nova realidade (McWilliams, 2004).

Desde o início do processo, considerou-se relevante o estabelecimento de uma boa aliança terapêutica como condição sine qua non para ser alcançável o sucesso terapêutico. $\mathrm{O}$ terapeuta deve respeitar incondicionalmente $o$ paciente, assim como manifestar com autenticidade, in- 
teresse, compreensão e aceitação pelo paciente, isento de qualquer atitude de julgamento. Deste modo, o paciente pode sentir-se livre e, também ele, evidenciar autenticidade e capacidade para se afastar de seus mecanismos de defesa, sendo capaz de enfrentar as adversidades (Rogers, 1974). De acordo com Marcelli (2002), para que o adolescente se envolva numa psicoterapia, é necessário, de sua parte, um mínimo de condições, entre as quais o estabelecimento de uma boa aliança terapêutica. $\mathrm{O}$ cariz desta relação com o paciente permite aduzir suficiente motivação e tolerância à frustração, o que pressupõe manifestação de interesse pelo seu mundo interior, mal-estar evidente e reconhecimento desse mal-estar.

Atendendo ao facto de Bruno reunir um conjunto de características inseridas neste quadro, tornou-se viável a possibilidade de o mesmo poder beneficiar de acompanhamento psicológico.

Em psicoterapia é pertinente que o terapeuta perceba o estado de sofrimento em que o paciente se encontra em torno de uma situação geradora de mal-estar, de modo a facilitar o processo. A mudança não é operada pelas atitudes ou intervenções do terapeuta, mas pela compreensão que o paciente adquire no contexto da terapia e na sequência de um trabalho dos sentimentos inerentes ao seu mal-estar. Particularmente em pacientes mais jovens, ainda que as atitudes parentais fossem passíveis de sofrer alterações, na verdade os filhos teriam que continuar a ter que se confrontar com os corolários daquilo que os pais lhes traduzem (McWilliams, 2004). Ou seja, na impossibilidade de mudar o passado, torna-se possível que Bruno, por meio de acompanhamento psicológico, aceite o presente e possa escolher o futuro. A psicoterapia breve de orientação psicodinâmica procura envolver ativamente o paciente na exploração de suas dificuldades, desenvolvendo suas capacidades de adaptação e seu potencial de desenvolvimento (Hobbs, 1999).

\section{Acompanhamento psicológico}

O processo de acompanhamento psicológico discorreu de forma individual, com periodicidade quinzenal e duração média de 45 minutos cada sessão, destacando-se o empenho e pontualidade de Bruno em comparecer às sessões.

Numa fase inicial, procedeu-se à recolha da história clínica com base numa primeira entrevista realizada a Bruno e posteriormente, na segunda sessão, com a colaboração da mãe do paciente.

Numa segunda fase, procedeu-se à recolha adicional de informação obtida a partir de uma avaliação psicológica, com a finalidade de um melhor e mais profundo conhecimento e compreensão das vivências e atual funcionamento do paciente.

O acompanhamento psicológico iniciou com o consentimento de Bruno, sendo que lhe foi comunicado que a consulta se tratava de um espaço onde apenas se abordariam os aspetos que o mesmo considerasse pertinentes, acreditando total sigilo e confidencialidade às sessões.
O processo foi facilitado pelo estabelecimento de uma relação empática entre paciente e terapeuta. De acordo com Rogers e Kinget (1975), a empatia expressa a capacidade de o terapeuta emergir no mundo subjetivo do paciente de modo a experienciar e compreender a realidade daquilo que é vivido e sentido pelo paciente. Porém o desenvolvimento da relação terapêutica compreende, também, a atitude do terapeuta. Este deve agir com autenticidade e congruência, bem como manifestar tolerância, aceitação, compreensão e respeito incondicional pelo paciente, assim como por aquilo que ele lhe transmite, isento de qualquer apreciação ou julgamento (Rogers, 1974; Rogers \& Kinget, 1975; Rogers, 2009).

Durante as primeiras sessões Bruno transparece um olhar cabisbaixo, estado de angústia e um percetível sofrimento interno de incerteza perante o futuro. Inicialmente adotou postura retraída, introvertida e algo defensiva, contudo, no discorrer das sessões, perfilhou as mesmas, como um espaço oportuno à partilha e vazão de suas inquietudes, emoções, vivências e seus sentimentos.

Na psicoterapia breve de orientação dinâmica o terapeuta é percecionado como autêntico, uma vez que aborda as transferências sem medo e rejeição na relação com o paciente. Após instaurada a confiança no terapeuta, o adolescente fala abertamente acerca de seus problemas e suas inquietudes, característico da fase desenvolvimental em que se encontra, favorecendo, de forma célere, a progressão do processo terapêutico (Hobbs, 1999).

Deste modo, na primeira sessão, Bruno enceta por expressar boa adaptação e normalidade face às vivências decorridas no último ano, aludindo "estar tudo bem" (sic). Na continuidade, manifesta mal-estar, desconforto e ansiedade quando confrontado, por algumas pessoas, perante o sucedido em sua família. Ressalta o facto de alguns colegas, familiares e sociedade em geral propenderem a aproximar-se dele com interesse em abordarem o episódio trágico, experimentando estigma por ser filho de um homicida (sic).

Bruno denota pouca disponibilidade por parte da figura materna e fraterna para abordar o assunto da reclusão da figura paterna, frisando que ambas tendem a evitar falar sobre os factos ocorridos, facto que the gera certo desconforto (sic).

Face ao homicídio ao qual assistiu, Bruno acresceu não ter sentido a morte do avô, contrariamente à sua irmã, pois enquanto esta tinha crescido em casa do avô, o paciente viveu desde sempre com o pai, descrito como seu cúmplice e uma figura de referência para si (sic). Aponta que atualmente apenas conversa com o pai uma vez por semana, ao Domingo, quando juntamente com a mãe e irmã se dirigem ao estabelecimento prisional onde o pai se encontra retido. Alude sentir-se bem ao visitar o pai, ainda que a visita seja curta, sublinha que o pai lhe dá muita força, embora saiba que quando se vem embora o pai chora (sic).

Após a reclusão do pai, manifesta ansiedade face ao exterior, isolando-se em seu quarto com o computador, receando que o abordem, descrevendo pensamentos recorrentes diante dos acontecimentos passados. Descreve, desde então, usufruir de pouco tempo livre, uma vez que 
ao sábado elabora as tarefas agrícolas que eram anteriormente incumbência do pai, expressando sentir-se satisfeito e realizado no desempenhar dessas funções (sic). Na continuidade, manifesta ansiedade, expressa por calor e palidez justificado pelo facto de no período da tarde o Juiz promulgar a sentença resultante do crime que o pai cometera. Bruno anuiu que o ideal seria que o pai não fosse acusado e voltasse para casa, para junto de si, contudo referencia temer o pior, uma vez que o próprio advogado não quisera pronunciar-se sobre isso (sic).

Na segunda sessão, Bruno evidencia maior tranquilidade. Refere que, após proferida, a decisão do tribunal lhe permite ter a certeza relativamente ao tempo que vai estar afastado da figura paterna, ressaltando a pena de 23 anos de prisão a que havia sido subjugado (sic). Na continuidade, alude o facto de não sentir motivação para sair, à exceção da escola, do curso de informática e da catequese. Ressalta saudades da figura paterna, descrevendo sentir orgulho no pai, considerado "um herói”, uma vez que, em sua infância, o pai havia sobrevivido a um linfoma (sic).

No decorrer da terceira sessão, Bruno expressa preocupação face aos fracos resultados que tem auferindo na escola, receando ficar retido no $8^{\circ}$ ano, o que representaria para si uma decepção à confiança do pai, pelo que acresce motivação, dedicação e esforço em melhorar os resultados (sic).

Bruno descreve sua vida nos últimos tempos como rotineira, sublinhando ter acordado muito cedo no dia anterior para visitar o pai. Salienta o facto de que sua vida seria diferente, caso não tivesse que fazer estas visitas (sic). Destaca uma parte de si que gosta de ir visitar o pai, pelo desejo de estar próximo e pela necessidade de demonstrar seu apoio incondicional; por outra parte aponta não gostar das visitas, pelo reavivar do sucedido e pelo sentimento de que existe uma possibilidade de sua ausência assumir um cariz mais prolongado. Neste sentido, Bruno descreve que, inicialmente, as visitas lhe causavam excessivo mal-estar, facto que tem vindo a diminuir com o decorrer do tempo, pela maior facilidade em gerir estes sentimentos, encontrando-se agora mais disponível para lutar junto do pai (sic).

A quarta e quinta sessão contemplaram dois momentos de avaliação. Bruno estabeleceu atitude relacional e colaborante face às tarefas propostas, aduzindo tranquilidade, concentração, atenção e estar à vontade no discorrer das mesmas.

Ainda que tenha conferido um estado emocional que não evidenciou preocupação significativa, tornou-se pertinente o acompanhamento de Bruno diante das vivências recentes, assim como monitorizado e sustentado seu rendimento escolar, uma vez que se tratou de um objetivo significativo para o paciente alcançar.

$\mathrm{Na}$ sexta sessão, Bruno manifesta preocupação pelas avaliações negativas em 5 unidades curriculares auferidas no término do $2^{\circ}$ período escolar, ressaltando que a maior preocupação, de momento, trata-se de conseguir transitar para o $9^{\circ}$ ano, destacando que se tratava da maior alegria que poderia dar ao seu pai (sic).
Por outro lado, acresce dificuldade em comunicar seus problemas e sentimentos com os outros, justificando o facto de se caracterizar como um adolescente, ressaltando timidez como característica sua desde a infância. Todavia, presentemente consigna o grupo de pares como prioritários em sua vida, desempenhando os familiares um papel mais secundário (sic).

A sétima sessão versou a devolução dos resultados da avaliação psicológica ao paciente. Bruno descreve o facto de a mãe impor um horário para regressar a casa, para estudar, bem como the exige assiduidade na escola e na catequese, facto que não parece acarretar conflitos pela sua concordância quanto aos limites (sic). Sublinha o apoio e suporte da figura materna; acresce denotar em si uma melhor capacidade para se adaptar à realidade e à ausência do pai. Manifesta o desenvolvimento de objetivos e ferramentas para minimizar o impacto das vivências, num momento particularmente mais difícil de sua vida, bem como da vida de sua família, de modo "a seguir em frente". (sic).

Na oitava sessão, Bruno manifesta otimismo devido a uma melhoria dos resultados nas disciplinas de Inglês e Espanhol, ressaltando que deste modo poderá transitar para o $9^{\circ}$ ano (sic). Pela primeira vez Bruno aborda uma temática inerente aos seus sentimentos e desejos românticos. Ressalta pertinência no que concerne à importância do desenvolvimento e estabelecimento de relações românticas na fase desenvolvimental em que se encontra, percecionando as mesmas como uma fonte de apoio supletivo face à ausência da figura paterna.

O suporte sentido pelos pares parece ter sido significativo para si, uma vez que aduz melhor adaptação à realidade, sublinhando sentir maior tranquilidade após a transferência do pai para o estabelecimento prisional onde se encontra presentemente. Ressalta satisfação pelo facto do pai, presentemente, beneficiar de melhores condições no que concerne ao espaço físico, podendo ainda desenvolver atividades recreativas e laborais que lhe aufere melhor qualidade de vida. Salienta ser preferível ver menos vezes o pai, mas saber que este se encontra mais seguro com melhores condições (sic).

À medida que o processo foi tendo continuidade, Bruno foi aceitando progressivamente seus sentimentos e clarificando a ambivalência e o medo sentido face à nova condição do pai. A intervenção do terapeuta não foi por isso pautada por técnicas específicas, mas por uma atitude paulatinamente atenta aos sentimentos inerentes às vivências diárias, ajudando o paciente a elaborá-las. Esta questão parece ter-se revertido em seu contexto alargado, nomeadamente na relação com a escola, com os pares amigos e pares românticos. E embora a relação com a mãe e a irmã ainda fosse bastante retraída sob o ponto de vista da expressão dos acontecimentos sucedidos, Bruno está já capaz de falar acerca de seus medos, angústias e expectativas.

A presente sessão constituiu um marco do processo terapêutico, destacando uma mudança na atitude relacional de Bruno. A atitude retraída e defensiva foi substituída por uma maior abertura, expressa num discurso algo ver- 
borreico. Expôs um conjunto de vivências, sentimentos e emoções significativas para si, acrescidas de um conjunto de alternativas que perceciona ao seu dispor, manifestando interesses e objetivos para sua vida. Percebeu-se de todo que Bruno sentia o espaço terapêutico como seu, estando agora mais disponível para confiar.

Na nona sessão, Bruno apresenta melhorias nos resultados das avaliações escolares, facto que vivencia com grande satisfação. Descreve maior participação nas aulas, ressaltando maior facilidade em desempenhar as tarefas e atividades de forma autónoma. Aduz maior à vontade na atualidade face aos colegas e professores, sublinhando revelar maior confiança nos mesmos. Justifica seu estado atual pelo facto de presentemente se sentir melhor consigo, o que lhe permite maior bem-estar com os demais, sobressaindo o desejo de nas próximas férias desfrutar de uns dias na aldeia, junto de um amigo, caso a mãe autorize (sic).

$\mathrm{Na}$ continuidade, refere ter visitado o pai recentemente, evidenciando-se a possibilidade de este poder beneficiar de uma redução na pena, na sequência de um pedido de recurso submetido pelo atual advogado. Emocionado, Bruno acresce a possibilidade de dentro de poucos anos poder voltar a partilhar a companhia do pai (sic). No final da presente sessão, a par da sessão anterior, quando analisadas as datas possíveis para agendar a próxima, o paciente opta por datas proximais, denotando o desenvolvimento de alguma dependência da terapia. Esta questão foi devolvida ao paciente, sendo relevante trabalhar o sentido de autonomia que Bruno está a construir.

$\mathrm{Na}$ décima sessão, Bruno manifesta contentamento pelos resultados escolares obtidos, tendo-lhe os mesmos permitido transitar para o $9^{\circ}$ ano de escolaridade, ressaltando ter atingido os objetivos a que se havia proposto (sic). No decorrer da sessão o paciente demonstra vontade para desfrutar do período de férias escolares sem necessidade de comparecer às sessões evidenciando um trabalho interior no sentido de desenvolver esforços face a uma maior autonomia. Neste sentido, Bruno acresceu o facto de atualmente percecionar uma diminuição da necessidade de visitar o pai com a frequência de anteriormente, optando por fazer visitas quinzenais (sic). Ressalta sua vontade em desviar a atenção focalizada, até então, na figura parental diante da atual primazia em prol da concretização de seus objetivos pessoais.

A décima primeira sessão contemplou o finalizar do processo terapêutico. No decorrer da mesma, Bruno mostrou-se tranquilo face a si mesmo assim como no que respeita à sua relação com os outros e meio circundante. Evidencia uma perspectiva otimista no que se refere à capacidade para enfrentar o futuro e possíveis obstáculos que possam surgir no percurso desenvolvimental. Bruno sublinhou maior abertura e disponibilidade para solicitar apoio psicológico na eventualidade de percecionar na continuidade eventuais dificuldades.

\section{Resultado do processo terapêutico}

No início do processo terapêutico, a atitude retraída e defensiva de Bruno indiciava alguma incerteza quanto à evolução e ao sucesso do processo terapêutico, enfatizado pelo facto de se tratar de um paciente que se encontra numa fase significativa de seu processo desenvolvimental. Porém o estabelecimento de uma boa aliança terapêutica apresentou-se como elemento essencial e significativo face à aceitação e adaptação de Bruno a uma nova realidade em seu quotidiano e sua dinâmica familiar. Nesta medida, não se pretendeu realizar uma psicoterapia de longa duração, mas uma abordagem focalizada nos conflitos internos ocasionados pela perda de uma figura significativa, acrescendo um contexto em que o paciente estaria implicado e, em certa medida, culpabilizado pelo desfecho. O foco de trabalho passou pelo acompanhamento progressivo da vivência do paciente, numa fase inicial conturbada, pautada pela revolta e a angústia, dando posteriormente lugar a uma maior organização interna e gestão dos sentimentos, permitindo-o estar mais disponível para si e para os demais.

Ainda que confrontado com vivências dolorosas, atualmente Bruno denota capacidade de aceitação dos factos e da ausência de uma figura parental significativa, outrora tão difícil de aceitar. Perceciona vivências de forte índole emocional como oportunidades de aprendizagem, crescimento pessoal e que são determinantes na construção de sua personalidade e no estabelecimento de objetivos e projetos de vida futura.

Igualmente significativo e contributivo para o sucesso terapêutico mostrou-se a opção pela terapia breve de orientação psicodinâmica, tendo em conta uma focalização na problemática enfatizada em consignar no paciente a capacidade de mudança, a partir da disponibilização de um espaço onde percecionou compreensão e pôde fazer seu luto (Hobbs, 1999; McWilliams, 2004).

A fase final do processo terapêutico incidiu na promoção da autonomia do paciente, de modo a que o mesmo fosse capaz de percorrer com confiança e segurança, e de forma autónoma, o restante percurso de vida. De acordo com Hobbs (1999), na fase final da terapia alguns pacientes podem evidenciar ambivalência, por um lado, diante da perspetiva de independência, contudo temendo a perda de apoio e responsabilidade acrescida.

Ao longo do processo terapêutico Bruno evidenciou mudanças significativas, à dada altura do processo o paciente libertou-se de sua atitude defensiva, aduzindo maior abertura e descontração nas sessões. Atendendo ao background de vivências anteriores, Bruno denotava relutância e desconfiança nas relações interpessoais, expressas num comportamento introvertido. A partir do momento que o paciente percecionou o espaço da consulta como um local seguro, e a terapeuta como alguém em que podia confiar, Bruno expressou um maior à vontade nas sessões. 


\section{Assuming the role of one's Father!: Psycotherapeutic intervention in adolescence}

Abstract: In this case study, the life experience of a 15 year old adolescent is addressed, specially the anguish and separation anxiety concerning the father figure, recently arrested due to parricide. The process began with a defensive, reluctant and suspicious attitude by the patient, with the verification of significant suffering related to the internal management of past experiences and a feeling of internal and external stigmatization. The evaluation reflects a resilient and adaptive adolescent, contrary to what would be expected in view of his recent experiences. However, some signs of depressive behavior were evident, including abulia, asthenia, and anhedonia, in addition to feelings of uneasiness and hopelessness for the future. A proposal of psychological intervention through brief psychotherapy of psychodynamic orientation in order to allow the resolution of internal conflicts that can compromise personality development and establishment of interpersonal relationships. In addition to diminishing symptoms, the intention was to clarify, organize and transform the internal conflicts in sustainable elements. The psychotherapy process, in parallel with the changes in the adolescent's relational dynamics allowed the occurrence of significant changes, specially a less defensive attitude and the ability to think about himself, tolerate and develop his feelings and emotions.

Keywords: adolescence, separation, internal conflicts, psychotherapy.

\section{Assumer le rôle du Père!: intervention psychothérapeutique dans l'adolescence}

Résumé: Cette étude de cas examine l'expérience d'un jeune de 15 ans, en soulignant l'anxiété et l'angoisse de séparation dans le visage de la figure du père, récemment recluse à cause de parricide. Le processus a commencé par une attitude défensive, réticents et méfiants par le patient, en pouvant vérifier une détresse sur la gestion interne des expériences passées et d'un sentiment de stigmatisation interne et externe. L'évaluation reflète un jeune adolescent résiliente et adapté, contrairement à ce qu'on pourrait attendre compte tenu des expériences récentes. Cependant, en évidence des signes de l'expérience dépressive se démarquer, natamment l'apathie, l'asténie e l'anhédonie, avec des sentiments d'inquiétude et de désespoir pour l'avenir. Été proposé une psychothérapie brève de orientation psychodynamique pour permettre de résoudre les conflits interne qui pourraient compromettre le développement de la personnalité et de l'établissement des relations interpersonnelles. En plus de réduire les symptômes ont cherché à organiser et transformer les conflits interne dans les éléments durables. Le processus de la psychothérapie, en parallèle des changements dans la dynamique relationnelle, a permis aux jeunes mettant en évidence des changements significatifs, en soulignant une attitude moins défensive et la capacité de penser à vous, à tolérer et à développer leurs sentiments et leurs émotions.

Mots-clés: adolescence, séparation, conflits internes, psychothérapie.

\section{Asumir el papel del Padre!: intervención psicoterapéutica en la adolescencia}

Resumen: Este estudio de caso describe la experiencia de un joven de 15 años, destacando la angustia y la ansiedad por la separación de la figura de su padre, recientemente recluso por parricidio. El proceso comenzó con una actitud defensiva, renuente y suspicaz por el paciente, comprobándose señales de sufrimiento en la gestión interna de las experiencias del pasado y un sentimiento de estigmatización interna y externa. La evaluación refleja un joven adolescente resistente y adaptable, en contra de lo que cabría esperar a la vista de las experiencias recientes. Sin embargo, destacan algunos signos de experiencia depresiva, como apatía, anhedonia y astenia, más la sensación de preocupación y desesperanza en el futuro. Se propone una intervención psicológica por vía de la psicoterapia de orientación psicodinámica breve con la finalidad de resolver los conflictos internos que puedan comprometer la formación de la personalidad y el establecimiento de relaciones interpersonales. Además de la disminución de los síntomas, se pretendió aclarar, organizar y transformar los conflictos internos en elementos sostenibles. El proceso de psicoterapia, en paralelo con los cambios en las dinámicas relacionales del joven produjeron cambios significativos que permiten poner en relieve una actitud menos defensiva y su capacidad para pensar en si mismo, tolerar y desarrollar sus sentimientos y emociones.

Palabras-clave: adolescencia, separación, conflictos internos, psicoterapia. 


\section{Referências}

Atger, F. (2004). Vinculação e adolescência. In N. Guedeney \& A. Guedeney (Eds.), Vinculação: conceitos e aplicações (pp. 147-153). Lisboa: Climepsi.

Barker, P. (2000). Fundamentos da terapia familiar. Lisboa: Climepsi.

Derogatis, L. (1994). SCL-90-R. Cuestionario de 90 Síntomas. Madrid: TEA Ediciones. (Adaptação espanhola por J. L. González De Rivera et al. (2002))

Fernandes, O. (2005). Ser único ou ser irmão. Dafundo: Oficina do Livro.

Hobbs, M. (1999). Psicoterapia breve de orientação dinâmica. In S. Bloch (Ed.), Uma introdução às psicoterapias (pp. 69-100). Lisboa: Climepsi.

Matos, C. (2007). A depressão. Lisboa: Climepsi.

Marcelli, D., \& Braconnier, A. (1989). Manual de psicopatologia do adolescente. Porto Alegre. RS: Masson.

Marcelli, D. (2002). Os estados depressivos na adolescência. Lisboa: Climepsi.
McArthur, D., \& Roberts, G. (1982). Roberts apperception test for children. California: Western Psychological Services.

McWilliams, N. (2004). Formulação psicanalítica de casos. Lisboa: Climepsi.

McWilliams, N. (2005). Diagnóstico psicanalítico. Lisboa: Climepsi.

Pratta, E., \& Santos, M. (2007). Família e adolescência: a influência do contexto familiar no desenvolvimento psicológico de seus membros. Psicologia em Estudo, $12(2), 247-256$

Rogers, C. (1974). Psicoterapia e consulta psicológica. Lisboa: Morais.

Rogers, C. (2009). Tornar-se pessoa. Lisboa: Padrões Culturais.

Rogers, C., \& Kinget, G. (1975). Psicoterapia e relações humanas. Belo Horizonte, MG: Interlivros.

Recebido: $25 / 03 / 2013$

$1^{\text {a }}$ revisão: $02 / 10 / 2013$

Aceito: $29 / 11 / 2013$ 